\title{
Forma urbana en Castilla-La Mancha
}

\author{
Antonio Zárate Martín *
}

\begin{abstract}
RESUMEN ABSTRACT
Las ciudades de Castilla-La Mancha muestran en su forma la huella de los diferentes procesos de urbanización que se han sucedido a través del tiempo, destacando dentro de ellas sus centros históricos por la importancia del patrimonio urbanístico

e histórico acumulado, la belleza y espectacularidad de sus emplazamientos. Muchas localidades, incluidas algunas de menor rango funcional y demográfico que las capitales, proporcionan un variado muestrario de respuestas urbanísticas

a necesidades concretas de las sociedades del pasado y se singularizan con fuerza dentro del patrimonio urbano español.

Las pulsaciones actuales de la dinámica urbana se dejan sentir en las ciudades principales a través de programas de conservación y recuperación de los espacios

The cities of Castille-La Mancha show in their shape the trace of the different urbanization processes following one another in time, standing out among them their historic centers, due to the importance of the urban and historic heritage gathered through the years, and to the beauty and spectacular nature of their sites. Many towns, including some with a less functional and demographic rank than the capitals, provide a varied collection of samples of urban responses to particular needs of the old societies, distinguishing themselves strongly among the urban Spanish heritage. The current beats of urban dynamics are being felt in the main cities through conservation and recovery of built spaces programs, supporting the filling of the gaps that exist in the built continuous, and also through the
\end{abstract}

\footnotetext{
* Profesor Titular de Análisis Geográfico Regional de la UNED.
} 
construidos, favoreciendo el relleno de los intersticios existentes en el continuo edificado, $y$ a través de la expansión de las periferias, con introducción de formas nuevas, extensas y difusas de urbanización. expansion of the outskirts, introducing new, extensive and widespread ways of building.

\section{UNA IMAGEN VISUAL DE LA CIUDAD}

La forma urbana hace referencia a la imagen visual de la ciudad, a su paisaje, y refleja estilos de vida, modelos y condiciones de organización socioeconómica que se han sucedido a través del tiempo. La forma es considerada como una estructura significante, que encierra, además, una fuerte carga de simbolismo en relación con las intenciones de los "productores" de la ciudad y con el contexto social de la construcción. Como indica Lasswell (1979), los elementos que integran la morfología urbana son la "firma del poder" que busca la admiración, el temor o el respeto de los administrados. De ahí también el creciente interés de la geografía de las representaciones mentales, desde planteamientos humanistas, por el análisis de la forma urbana.

El plano, la construcción, los usos del suelo son los elementos esenciales del paisaje urbano, junto con el entorno geográfico que determina el emplazamiento y la situación de la ciudad. Todos ellos constituyen la forma, son un verdadero lenguaje espacial e integran lo que Albert Levy (1965) denomina el "continente" o la sustancia física de la ciudad frente al "Contenido" (la sustancia social).

En definitiva, el paisaje aparece ante todo como producto social que muestra la huella del pasado histórico, las condiciones que determinaron la creación de la ciudad y su emplazamiento y situación en un espacio físico concreto. Las características de estilo de la construcción, el entramado y el trazado del plano se relacionan con las funciones que acompañan las distintas fases de crecimiento de las ciudades. La forma urbana exterioriza las condiciones sociales, culturales, económicas y tecnológicas y los valores simbolicos, de naturaleza cambiante que han intervenido en su construcción. Todo ello permite identificar regiones o áreas morfológicas bien definidas dentro de la ciudad.

El estudio de la forma analiza como la ciudad llega a ser lo que es, que partes la integran y cual es la lógica de la organización del entramado urbano. Se combina asi un tratamiento diacrónico, que investiga su crecimiento, y un tratamiento sincrónico, que pone de relieve las diferentes par- 
tes de la ciudad, su organización y las relaciones existentes entre ellas. De ese modo se consigue una mayor comprensión de la estructura urbana y una mejor valoración de su funcionamiento global para intervenir en ella corrigiendo problemas y desequilibrios actuales. A través de la forma se descubren conflictos que han contribuido a modelar la ciudad en cada momento histórico, así como fenómenos de densificación y sustitución que se producen frecuentemente sin apenas alterar o transformar su planta.

Las ciudades castellano-manchegas, al igual que las de cualquier otro territorio, son estructuras complejas que permiten distinguir espacios interiores bien diferenciados desde el punto de vista del análisis formal. Configuración del plano, entramados y tipologías edificatorias responden a los condicionamientos de sus respectivos entornos geográficos y a la sobreimposición de modelos urbanos diferentes en función de las transformaciones económicas, políticas y sociales que han acompañado a los diferentes modos productivos y concepciones del mundo que se han sucedido en el tiempo.

A pesar del reducido volumen de población de las ciudades castellano manchegas (sólo Albacete rebasa los 100.000 h.), las capitales provinciales y las otras ciudades de mayor rango y dinamismo, como Talavera de la Reina y Puertollano, tienden a convertirse cada vez más en espacios difusos que engloban dentro de su área de influencia inmediata núcleos rurales próximos y urbanizaciones recientes según el modelo de suburbani-

\section{Evolución de la Población}

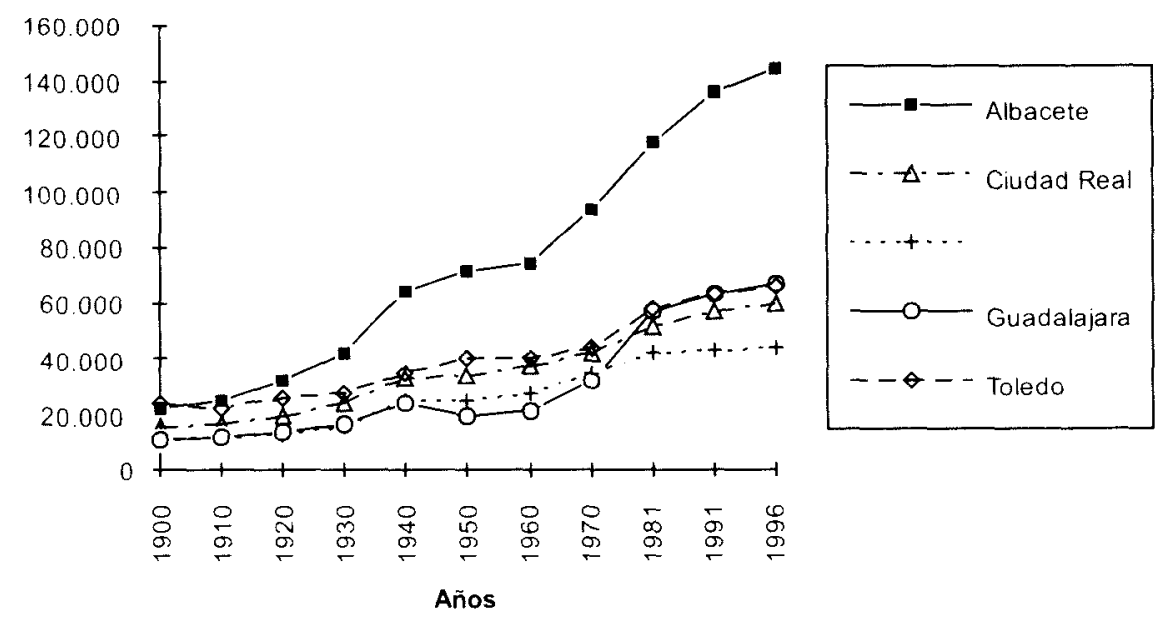

Fuente: Censos de Población y Padrón 
zación imperante en el mundo. Toledo, con $66.989 \mathrm{~h}$, potenciada por su función de capital regional, genera unos flujos de actividad y de movilidad poblacional que afectan a los pueblos de su entorno. Hasta tal punto esto es así que su Ayuntamiento ha planteado la creación de un área administrativa metropolitana con las municipios de de su área de influencia inmediata para armonizar políticas de suelo y resolver problemas comunes de ordenación del territorio.

\section{LOS CENTROS HISTÓRICOS, FORMA COMPACTA Y UTILIZACIÓN INTENSIVA DEL SUELO}

Dentro de la forma extensa de ciudad que hoy predomina, los centros históricos son los espacios de mayor personalidad paisajística por la originalidad de sus emplazamientos, características de los planos, naturaleza de los entramados, variedad de las tipologías edificatorias y acumuación de monumentos.

El origen defensivo de la mayoría de las ciudades castellanomanchegas, bien en la Antigüedad, como Guadalajara, Toledo o Talavera de la Reina (situadas estratégicamente en el corredor natural Este-Oeste de los ríos Henares y Tajo y sobre la vía romana de Caesar Augusta a Emerita), o en la Edad Media, como Cuenca, Puertollano, Manzanares, Alcázar de San Juan (en las inmediaciones de los sistemas montañosos y en la Mancha, en relación con la disputa del territorio por cristianos y musulmanes), explican la elección de emplazamientos privilegiados para responder a una finalidad militar y para un desarrollo urbano acorde con las necesidades de aquellas épocas. Desde entonces a nuestros días, esos emplazamientos han actuado como el principal condicionante de la estructura urbana y como un inconveniente para adecuar el funcionamiento de las ciudades a las exigencias de la sociedad actual.

Toledo, sobre un fragmento del zócalo cristalino de los Montes de Toledo que individualiza el torno epigénico del Tajo, y Cuenca, en el espolón formado por la erosión de los ríos Júcar y Húecar, constituyen los dos ejemplos más significativos de emplazamiento defensivo y de fuerte condicionamiento de la forma urbana por la topografía. En ambos casos, el emplazamiento determinó el trazado de sus vías principales, facilitó la construcción de murallas y obligó en los momentos de máximo crecimiento demográfico a una ocupación intensiva del territorio, con apropiación del vuelo de las calles por los particulares (cobertizos en Toledo), aumento de alturas (casas colgantes en Cuenca) y un entramado urbano cerrado. 


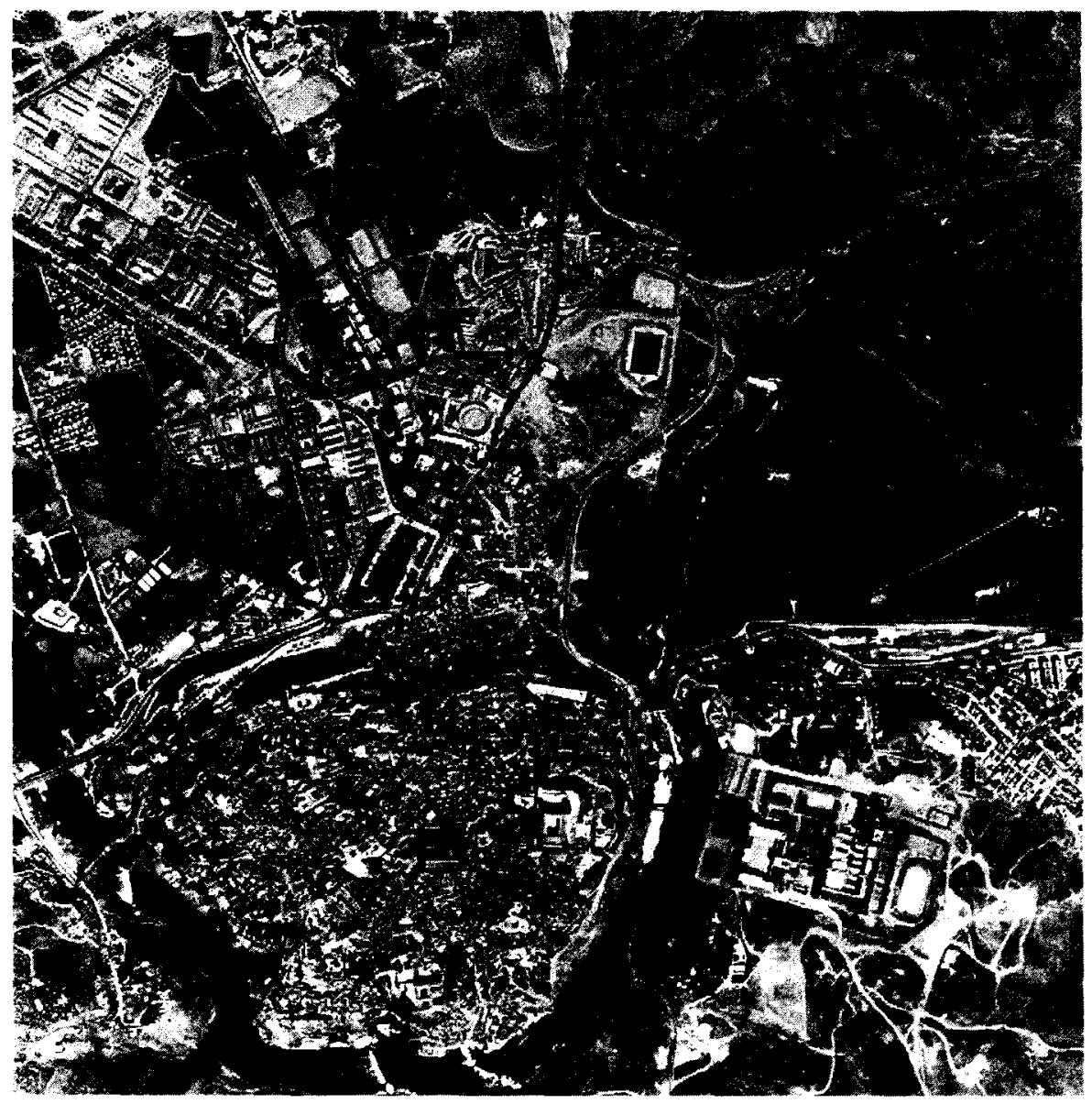

Figura 1. Emplazamiento de Toledo.

Tras la construcción de arrabales medievales, hubo que esperar a los siglos $X V$ y $X V I$ para que aparecieran extramuros algunos nuevos barrios, como los de las Covachuelas, la Antequeruela, San Antón y San Martín en Toledo, o los de San Antón, a la derecha del Júcar, y Tiradores, a la izquierda del Húecar, en Cuenca. Después no habrá más expansiones hasta finales del siglo XIX, con la llegada del ferrocarril, y ello de forma muy tímida.

La tipología de los planos de las cascos históricos de las ciudades castellano-manchegas responde a las condiciones físicas de su emplazamiento, a factores de tipo político, económico, social, cultural y a un crecimiento 
espontáneo en la mayoría de ellos, sobre todo en los correspondientes a ciudades que alcanzaron importancia en tiempos del Islam, como Toledo, Talavera de la Reina o Guadalajara, o que fueron fundadas entonces, como Cuenca. Los centros de estas ciudades, y de manera muy especial Toledo, presentan planos y estructuras análogas a las de cualquier medina del norte de Africa. Las calles son tortuosas y de desigual anchura, algunas están cubiertas por viviendas que pasan de una lado a otro de la vía, muchas son callejones sin salida (adarves) que se cerraban con una puerta de madera durante la noche por razones de seguridad. También hay plazas interiores que se cerraban al llegar la noche por idénticos motivos (corrales, como el de Don Diego en Toledo). En todos estos casos se trata de una organización del espacio condicionada por una estructura jurídica que facilita la ocupación espontánea del suelo por los particulares, por una sensibilidad estética que antepone los espacios cerrados a los abiertos y por razones de tipo político y social que impulsan la compartimentación.

La convivencia pacífica durante siglos de cristianos, judíos y moriscos dentro de las ciudades dio origen a juderías y morerías (barrios perfectamente diferenciados e individualizados mediante cercas o murallas interiores) cuyas huellas perduran en nuestro paisaje urbano. Del mismo modo, los recintos correspondientes a la al-mudaina, la fortaleza o ciudad oficial durante la época musulmana, donde se encontraba la residencia del gobernador y se alojaba la guarnición, con su propio recinto de murallas, se reconocen facilmente en Toledo, Cuenca, Talavera de la Reina y Guadalajara.

Los planos de los centros históricos de las ciudades de origen cristiano, fundadas durante los siglos XII y XIII, presentan en general una traza más regular. La mayoría ofrecen una estructura radioconcéntrica, como Ciudad Real, Puertollano o Alcázar de San Juan. Las vías partían de una plaza principal, la iglesia o la fortaleza, y terminaban en las puertas de las murallas. También existen planos regulares del tipo bastida, como Manzanares, donde el entramado se organiza en torno a una vía principal que unía el castillo con la iglesia y dos calles longitudinales, paralelas a la anterior y a la muralla, y calles transversales. A partir de ese núcleo fundacional y una vez desaparecidas las murallas, las vías principales han adoptado una disposición radial siguiendo el trazado de antiguos caminos hacia los pueblos vecinos y hacia la estación (A. Zárate, 1985).

El entramado, la tipología de los edificios y el volumen de la construcción de las ciudades castellano-manchegas reflejan los mismos factores económicos, sociales, políticos y tecnológicos que modelaron sus planos y responden también a los valores colectivos de la sociedad que se han ido 
modificando con el paso del tiempo en respuesta a estilos de vida, modos de organización socioeconómica y concepciones del poder dominantes. Por eso los centros históricos acumulan la carga simbólica de las ciudades y representan mejor que ningún otro espacio su memoria colectiva.

En Toledo, Cuenca, Ciudad Real, Guadalajara y Talavera de la Reina, los edificios ocupan de manera compacta el territorio correspondiente a la ciudad medieval, perfectamente delimitada en el pasado por murallas que servian de defensa y garantizaban el estatus jurídico de sus habitantes. Durante siglos, la ocupación de su suelo respondió a los limites impuestos por la muralla y a la imposibilidad de efectuar grandes desplazamientos fuera de ella por las carencias tecnológicas de los transportes. Desde el siglo XIX a la gran expansión urbana de los años 60 , la necesidad de adaptar las ciudades a nuevas estructuras productivas, a esquemas de organización social diferentes y a un crecimiento poblacional rápido dentro del modelo de transición demográfica, impuso una ocupación más intensiva del suelo y una mayor densificación de los espacios construidos.

Las tipologías edificatorias, la altura y el volumen de la construcción de los cascos históricos presentan diferencias de unos a otros según el desigual dinamismo de las ciudades a las que pertenecen, la naturaleza predominante de sus actividades y la posición jerárquica que cada localidad ha ocupado a través del tiempo dentro del sistema urbano catellanomanchego. Las normas legales de planeamiento que condicionan la producción del espacio físico, como Planes Generales de Ordenación Urbana y Planes Especiales de Reforma Interior, y las medidas de protección y conservación del patrimonio histórico artistico también han tenido una incidencia desigual. De ese modo, la mayor densidad, altura de edificios y volumen de construcción corresponde a los centros de Albacete y Ciudad Real, con procesos muy fuertes de renovación en los años sesenta y setenta por sus ventajas de centralidad para las funciones terciarias dentro de sus respectivas estructuras urbanas y por la ausencia de monumentos importantes. Los Planes Generales de Ordenación de 1963 y 1974 en Albacete y de 1963 en Ciudad Real facilitaron la renovación de estos espacios. Hoy, predominan dentro de ellos la construcción moderna y la edificación en altura.

Por el contrario, los cascos de Toledo y Cuenca han conservado bien las tipologias edificatorias y las tramas urbanas heredadas, debido a la importancia de su patrimonio monumental y a la existencia de rígidas normas de protección de paisaje. En Toledo, según su Plan Especial, hay 112 edificios catalogados como monumentos y otros muchos quedan bajo diferentes niveles de protección al entrar dentro de tipologias de valor his- 
tórico: casonas, casas patio de grandes proporciones inspiradas en la villa romana con influencias islámicas y cristianas, casas-patio, de menores proporciones que las anteriores, casas-patio entre medianeras, casas sin patio y bloques de viviendas, que tienen interés arquitectónico por sus estilos modernista o neomudejar.

Los centros históricos de Talavera de la Reina, Guadalajara y Puertollano ocupan una posición intermedia respecto a los dos grupos de ciudades anteriores en cuanto a la transformación y conservación de sus paisajes, pero en cualquier caso también son espacios de acusada personalidad dentro de sus respectivos conjuntos urbanos. En Talavera de la Reina (una de las ciudades de la región de mayores transformaciones morfológicas durante los años 60 por la ausencia de Plan General de Ordenación Urbana hasta su aprobación por el Pleno Municipal del 13 de junio de 1994), se conservan puertas y lienzos de murallas de los distintos recintos musulmanes e interesantes edificios de un pasado más reciente, algunos, como el teatro Victoria, magníficamente recuperados.

Los procesos de revitalización funcional y social experimentados durante el siglo XIX por las ciudades castellano-manchegas que fueron designadas capitales provinciales en 1833 , dentro del modelo de organización político territorial de Javier de Burgos y en el marco de las trasformaciones impuestas por la consolidación del Estado liberal burgués de derecho, dejaron su huella paisajística a través de edificios institucionales (Diputaciones, Delegaciones Ministeriales), asistenciales (Psiquiátricos, Hospitales, Asilos), educativos (Institutos de Enseñanza Media, Escuelas Normales, Colegios) y bloques de viviendas de 405 plantas, con patio de vecindad, que ocasionalmente encierran valor arquitectónico por sus estilos modernistas o neomudejares.

La Desamortización facilitó también la renovación y transformación morfológica de las ciudades castellano-manchegas en el siglo XIX. Muchos de los edificios institucionales construidos entonces se levantan sobre antiguos conventos, iglesias o propiedades de la Iglesia. La fachada norte de Toledo cambió su perfil tradicional, iglesias y conventos dieron paso a edificios institucionales (Diputación Provincial, Sanidad y Hospital Psiquiátrico, en la actualidad Consejería de Hacienda). Además, la desvinculación de bienes eclesiásticos proporcionó en la mayoria de los casos suelo urbanizable para usos más intensivos, para el trazado de plazas y la apertura de parques.

El desarrollo de la burguesía local se tradujo urbanísticamente en la construcción de multifamiliares según los modelos arquitectónicos de los ensanches de Madrid y Barcelona. En Toledo, las nuevas estructuras re- 
sidenciales se concentraron en los puntos de mayor centralidad y accesibilidad, cuesta de las Armas, calle del Comercio y entorno de la plaza de Zocodover; en Cuenca, en las vías y plazas principales de la Ciudad Alta y de la Ciudad Baja, y en Albacete, a lo largo de las vías que parten del núcleo fundacional y se construyen entonces, debido al reducido tamaño del emplazamiento primitivo y al fuerte empuje de la ciudad desde la llegada del ferrocarril en 1855. Entre 1900 y 1940, la población albaceteña se triplicó y en la segunda década del nuestro siglo se configura la morfología actual de las calles comerciales Marques de Molins y Tesifonte, con construcciones de interés arquitectónico (Panadero, M., 1976).

La edificación tradicional, de viviendas unifamiliares de una o dos plantas, perdura hasta nuestros días en todas las localidades castellano-manchegas y ocupa gran extensión en los centros históricos más importantes: en Toledo, dentro del espacio delimitado por el meandro epigénico, y en Ciudad Real, dentro del enorme recinto definido por la ronda de circunvalación que corresponde al trazado de su primitiva muralla. Los Planes Generales de Ordenación en Ciudad Real y las normativas de protección de paisaje y del Plan Especial en Toledo consolidan estas formas de viviendas en las zonas donde ya existen. En cambio, estas construcciones han adquirido un carácter más residual en las áreas centrales de Albacete, Talavera de la Reina y Guadalajara por efecto de sus dinámicas urbanas internas.

\section{BARRIOS POPULARES EXTRAMUROS: EL IMPACTO DEL FERROCARRIL Y LA INDUSTRIA}

Más allá del casco medieval, del espacio delimitado en el pasado por las antiguas murallas, empieza la ciudad dispersa en todos los casos, la ciudad que han ido surgiendo a través de sucesivas expansiones desde finales del XIx hasta nuestros días. Sus planos, características de construcción y entramados ofrecen formas variadas en función de los factores de producción dominantes, los sistemas de propiedad existentes, las necesidades de suelo urbano impuestas por el aumento demográfico y los cambiós tecnológicos, y las operaciones de actuación urbanística que han organizado estos territorios para acomodarlos a objetivos de rentabilidad económica. Dentro de estas zonas, los ferrocarriles, las carreteras, las infraestructuras, los depósitos de abastecimiento de agua, los parques públicos aparecen como líneas de fijación que durante un tiempo limitaron el crecimiento de la ciudad, y luego, como puntos de origen de zonas de expansión que terminan por configurar el modelo actual de ciudad difusa. 
En todas partes el ferrocarril ha sido un importante agente de transformación de la forma urbana, además de contribuir a dinamizar la vida de la ciudad y a favorecer su renovación interna. En torno a las estaciones surgieron barrios de casas de una o dos plantas, en unos casos lejos del centro y mal integrados, como sucede en Toledo, y en otros, más próximos y más fácilmente integrados en el tejido urbano, como en Cuenca, Guadalajara o Albacete. La mayoría fueron núcleos de crecimiento espontáneo y trazado irregular, cuyas viviendas eran ocupadas por ferroviarios o trabajadores no cualificados. La necesidad de comunicar la estación con la ciudad determinó frecuentemente el trazado de calles que pronto acabaron convertidas en vías principales.

En Albacete, la estación orientó uno de los sentidos del crecimiento de la ciudad, a través de las calles de Salamanca y del Progreso, y hacia 1930, propició la aparición del "Barrio de la Industria», al Noroeste. El traslado de la estación unos centenares de metros más al Norte, en el marco del Plan General de Ordenación Urbana de 1974, definió nuevamente una de las principales zonas de expansión urbana de esta capital (Panadero, M., 1976).

En esta misma ciudad, la construcción de la Carretera de circunvalación en dirección opuesta a la estación, por el Sur, a partir de 1930, para desviar el tráfico de la carretera nacional de Madrid Alicante, generó un extenso perímetro urbano a modo de ensanche de población que se iría colmatando lentamente. La prolongación de las vías de salida del primitivo recinto hacia el exterior y el trazado de calles nuevas en arco de círculo completaron la actual estructura radioconcéntrica del plano de Albacete y propiciaron la edificación de gran parte de él en manzana cerrada.

En Cuenca, la llegada del ferrocarril en 1883 impulsó el traslado de las clases sociales de mayores niveles de renta de la Ciudad Alta a la Ciudad Baja, hacia el Este, y la ordenación de esta zona a través de los Planes de Urbanización de 1885 y de Alineaciones de 1887 (Troitiño, M.A., 1984).

También en Ciudad Real la estación del ferrocarril, al Este del perímetro medieval, dio origen entre 1921 y 1940 a barrios habitados por ferroviarios y trabajadores de escasa cualificación. En la actualidad, la estación del AVE hace de esta zona una de las de mayor crecimiento y dinamismo.

Las carreteras y vias de salida de todas las ciudades atrajeron desde finales del siglo $x \mid x$ y principios del $x x$ pequeños almacenes y talleres, $y$ facilitaron el nacimiento o ampliación de barrios populares, de viviendas de una o dos plantas, que casi siempre conservan una tipología de casa rural y a veces son de autoconstrucción, con materiales de mala calidad o de 
Núcleo medieval

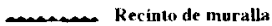

Mediados del siglo $X \mid X$

De 1875 a 1920

De 1921 a 1940

De 1941 a 1960

De 1961 a 1985

Despues de 1985

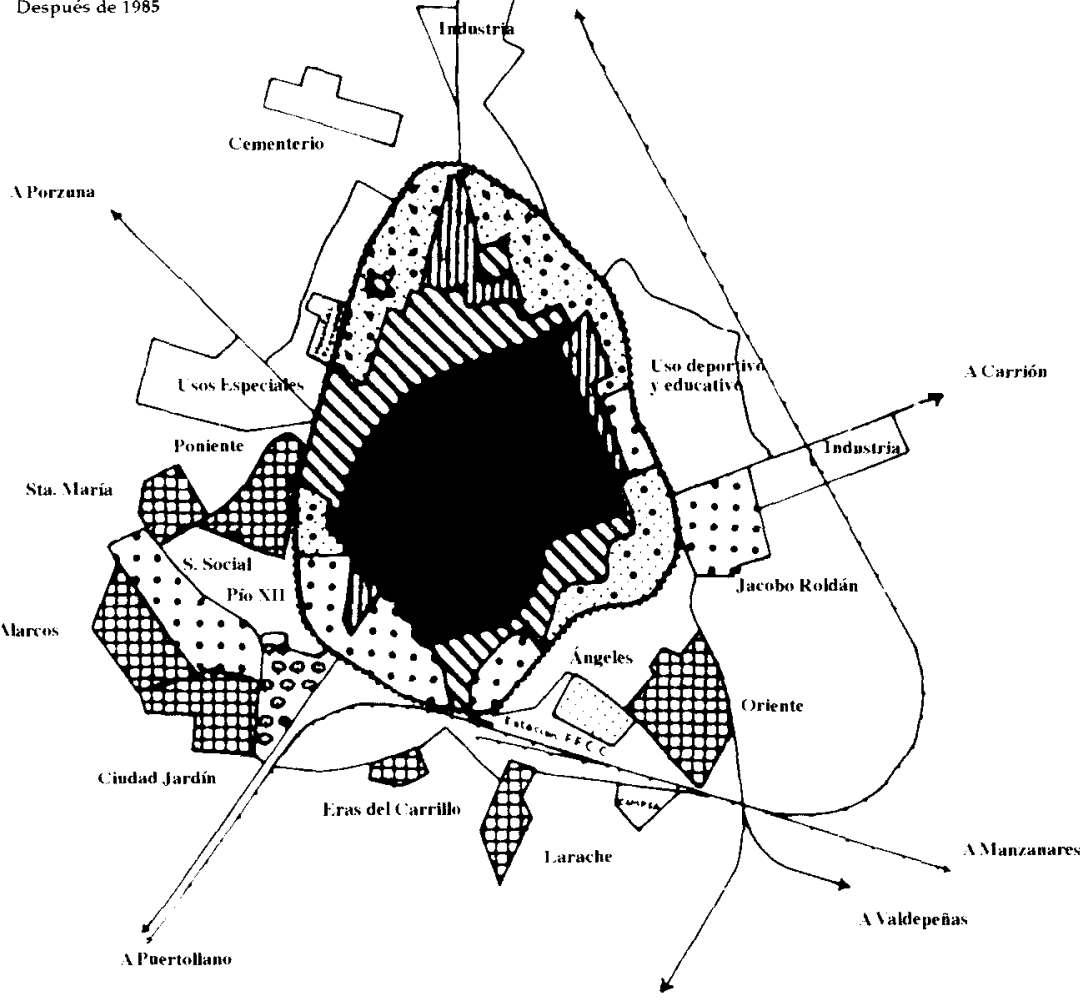

SCalyada de Calatrava

Figura 2. Desarrollo urbano de Ciudad Real.

desecho. En Toledo, se consolidaron así los barrios de San Antón, San Martín y Santa Bárbara. Todos ellos sobre suelos municipales que se ocuparon de forma espontánea, luego legalizados mediante régimen de canon, y en fechas muy recientes, cedidos por el Ayuntamiento en propie- 
dad a sus vecinos. En Cuenca, los barrios de San Antón y Tiradores actuaron como suburbios populosos de crecimiento espontáneo e irregular.

Dentro de la tipología de barrios populares de naturaleza espontánea y de autoconstrucción tienen especial importancia por su extensión e impacto morfológico los que surgieron en Puertollano a raíz del inicio de la explotación de su minería en 1873. Las minas y las industrias vinculadas a ella impulsaron desde finales del $\mathrm{XIX}$ a los años 40 de nuestro siglo una considerable corriente inmigratoria que dio origen a barrios mineros, de autoconstrucción, por las faldas de los cerros de San Agustín, San Sebastián y Santa Ana, y por el sur, cerca de las minas, en un amplio semicírculo comprendido entre la línea del ferrocarril de Ciudad Real a Badajoz y la carretera de Calzada de Calatrava. Todos ellos se asientan sobre suelos inapropiados para la construcción por su fuerte pendiente 0 por situarse muy próximos a zonas de hundimiento. Las viviendas son unifamiliares y de una sola planta, se construyen con materiales de mala calidad, las condiciones higiénicas y sanitarias son escasas y su distribución sobre el plano se realiza en forma de cuadricula superpuesta a la fuerte pendiente de las colinas (Zárate, A. 1985).

Al amparo de las Leyes de Casas Baratas e influidos por las corrientes higienistas que buscaban el acercamiento del campo a la ciudad y por planteamientos sociales que propugnaban mejores condiciones de vida para las clases trabajadoras, empezaron a surgir en los años veinte y treinta barrios populares de viviendas unifamiliares con un pequeño jardín, como los de Larache y la Ciudad Jardín en Ciudad Real. El primero para ferroviarios y el segundo para funcionarios (Pillet, F., 1984).

\section{EXPANSIONES URBANAS DE POSGUERRA: LAS RESPUESTAS AL DÉFICIT ACUMULADO DE VIVIENDAS}

Las tipologías de viviendas unifamiliares de carácter social, con pequeño jardín, se repiten en las expansiones urbanas de posguerra, en los años cuarenta y cincuenta, como una de las respuestas al déficit de alojamientos resultante de las destrucciones de guerra, del inicio del fuerte éxodo rural y del rápido crecimiento demográfico de aquellos años. Ahora fue exclusivamente la iniciativa oficial la que promovió la construcción de estos barrios. Por entonces se construyeron el poblado obrero de la Fábrica de Armas y los unifamiliares de la carretera de Avila en Toledo, la barriada de Jacobo Roldán en Ciudad Real, la "colonia de Sindicatos" en la calle de Fernández Iparraguirre en Guadalajara (García Ballesteros, A., 1978), los barrios de viviendas baratas de la Piedad y Ramón Corrochano 
en Talavera de la Reina, hacia el Norte, entre la avenida de Pío XII y la Alameda al Este. En Cuenca, el Estado construyó la Colonia Virgen de la Luz a través de la Obra Sindical del Hogar y los grupos de San Julián y General Fanjul, este último cerca de la estación.

Dentro de los barrios de viviendas unifamiliares de aquellos años resultan especialmente representativos por sus dimensiones y carácter los que se construyeron en Puertollano, aprovechando su prosperidad y crecimiento como consecuencia de la creación del complejo petroquímico "Calvo Sotelo» por el INI, en plena autarquía, a partir del petróleo obtenido de la destilación de las pizarras bituminosas de la zona y posteriormente del traído por un oleoducto desde Málaga. EI INI levantó una ciudad jardín para sus trabajadores al Este de la ciudad, el poblado "Calvo Sotelo", junto a la carretera de Calzada de Calatrava, cerca de las instalaciones petroquímicas pero separadas de ellas. Las viviendas están rodeadas de un jardín y su tamaño y características se ajustan a la categoría profesional de los trabajadores a los que iban destinadas. A su lado, al Sur de la misma carretera, se construyó poco después la barriada de las «309», también a base de viviendas unifamiliares pero de menor calidad.

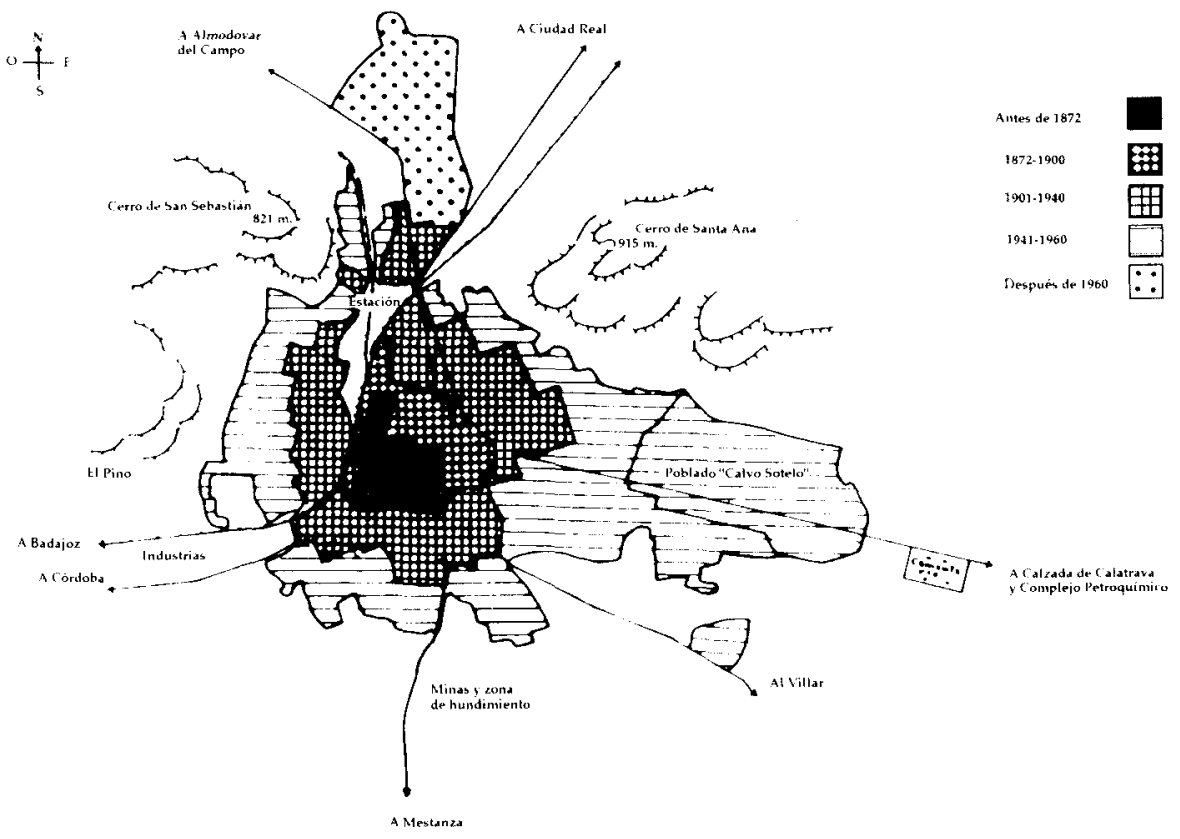

Figura 3. Desarrollo urbano de Puertollano. 
Las mismas necesidades de reconstrucción y de hacer frente al grave problema de la vivienda, así como la falta de interés de la iniciativa privada por la construcción (entre otras razones por las dificultades de adquisición y transporte de materiales y su elevado coste), determinaron la edificación por el Estado de multifamiliares en bloques laminares o manzanas cerradas, primero a través de la Dirección General de Regiones Devastadas, y luego a través del Instituto Nacional de la Vivienda u organismos afines como el Institulo Nacional de Previsión o la Obras Sindical del Hogar. Sobre suelos rurales próximos, generalmente municipales y cedidos de forma gratuita, surgieron entre otros muchos los bloques de la avenida de la Reconquista en Toledo, levantados por Regiones Devastadas, los barrios de Jacobo Roldán o del Pilar en Ciudad Real, los grupos de Santa María y Padre Ayala en esa misma ciudad, el grupo de viviendas "defensores de Guadalajara» y los barrios de San Isidro y Nuestra Sra de la Antigua en Guadalajara, o el barrio del "Hogar Sindical" en Albacete. En Cuenca, el Ayuntamiento construyó y urbanizó zonas situadas al sur de la Ciudad Baja, en las proximidades de la plaza de Toros y entre el ferrocarril y la carretera de Alcázar (Troitiño, M. A.,1984).

También abundaron en los años cincuenta actuaciones sobre descampados y solares próximos al centro que se acometieron como obras de reforma interior. Uno de los ejemplos más significativos corresponde a Ciudad Real, en la zona comprendida entre las calles de Alfonso X el Sabio, Avenida de los Mártires y Paseo de Cisneros. Sobre una gran superficie sin edificar, la Obra Sindical del Hogar construyó viviendas sociales y edificios para organismos públicos que pronto se revalorizaron urbanísticamente por sus ventajas de centralidad (Pillet, F., 1984).

Las características morfológicas de los barrios oficiales de los años cuarenta y cincuenta responden a una construcción en manzanas o a bloques laminares. El entramado, naturaleza y calidad arquitectónica varían en función de su localización dentro del conjunto de la ciudad y de la categoría social de los habitantes para los que se destinaron: funcionarios, militares, trabajadores cualificados, trabajadores no especializados o programas de erradicación del chabolismo. En las actuaciones de mayor centralidad (avenida del Rey Santo en Ciudad Real) o de mayor calidad ambiental y paisajística (avenida de la Reconquista en Toledo), la arquitectura $y$ el diseño se enmarcan dentro de lo que en el urbanismo español se ha denominado la "ciudad falangista". La creación de suelo urbano era justificada como la necesidad de terminar la ciudad construida, los edificios eran envueltos en una retórica historicista que utilizaba sistemáticamente los elementos más castizos de la arquitectura de los siglos XVI y XVII (co- 
lumnas, pórticos, frontones, decoración de bolas, etc) y los materiales más típicos, ladrillo rojo en los paramentos e hiladas de piedra en las esquinas. El trazado de las vías principales responde a deseos monumentalistas que recurren a las perspectivas barrocas y a una toponimia grandilocuente relacionada con el pasado imperial y la Reconquista como bases de la interpretación oficial de la historia por aquellos años.

Todo este tratamiento urbanístico estuvo muy influido por Giménez Caballero, consejero nacional de Falange e ideólogo que elaboró una especie de teoría arquitectónica del régimen. A través de la arquitectura se hacia una interpretación de nuestra historia. La piedra representaba la España romana y cristiana, el elemento matriz y tradicional, el ladrillo simbolizaba la España morisca y judía. La utilización del ladrillo en el paramento enmarcado por la piedra significaba el sometimiento del substrato judío y morisco al cristiano y también el triunfo de los cristianos sobre los infieles, de los "nacionales" sobre los "rojos". A la vez, se establecia un trasfondo racial en la dialéctica de los materiales por cuanto el «rojo ladrillar» representaba el "sustrato humilde", el "elemento ibérico indígena", dominado por la piedra y la pizarra, «el sentido ario y occidental del mundo" (Díaz Nosty, B. y Sueiro, D., 1977).

La insuficiencia de la iniciativa oficial para atender las necesidades de vivienda, a pesar de los esfuerzos realizados, hizo crecer un urbanismo marginal semejante al que surgia en el resto del Estado, unas veces sobre antiguos asentamientos, como la Antequeruela, San Antón y Santa Bárbara en Toledo, otras, dando origen a fenómenos de infravivienda y chabolismo. Precisamente fue por entonces cuando empezó a expandirse la barriada toledana de Santa Bárbara, en parte con inmigrantes de la propia provincia y en parte con presos políticos que por el día trabajaban en la construcción de la nueva Academia Militar y por la tarde construían sus viviendas con materiales de derribo del Alcázar. Con el paso del tiempo, la mayoría de aquellos barrios fueron mejorados mediante autoconstrucción por sus propios vecinos y con la instalación de servicios y equipamientos comunales adecuados a sus necesidades a partir de la década de los 70 , casi siempre como consecuencia de la presión ciudadana sobre los ayuntamientos.

La mayoría de los asentamientos de infravivienda de posguerra fueron derribados ya a finales de los años cincuenta y principios de los sesenta, y sus vecinos, realojados en barrios de absorción, con tipologías también muy características, a base de bloques laminares de 3 o 4 plantas y viviendas de escasa dimensiones y bajos niveles de calidad. El barrio de "Corea» en Toledo es un ejemplo representativo. 


\section{PLANEAMIENTO Y FORMA URBANA: LA CIUDAD ZONIFICADA}

La incidencia del planeamiento oficial en la forma de las ciudades ha sido fundamental, a pesar de que con excesiva frecuencia sus normas no sólo no han sido respetadas sino que han servido para encubrir operaciones de especulación y de renovación radical de los espacios construidos al servicio de los intereses económicos y sociales dominantes. Los Planes Generales de Ciudad Real y Albacete han propiciado de manera especial la eliminación de tramas históricas, cambios morfológicos con aumento de la volumetría y la altura de los edificios, y fenómenos de "invasión-sucesión" funcional y social en sus correspondientes centros urbanos.

Dentro de Castilla la Mancha, los primeros Planes de Ordenación Urbana, anteriores a la Ley del Suelo de 1956, corresponden a Cuenca, Toledo y Albacete. Ya en 1885, Cuenca dispuso de un Plan de Urbanización, modificado por un Plan de Alineaciones en 1887, que contribuyó a configurar la Ciudad Baja como sede de actividades comerciales e industriales, y en 1941 contó con un Proyecto de Ordenación General que diseñaba su expansión por el camino de Cañete y las carreteras de Valencia y de Alcázar, en este último caso en estrecha relación con una zona industrial de crecimiento espontáneo cercana al ferrocarril. Ese Plan planteaba por primera vez la conservación y protección del Centro Histórico y la mejora de los barrios de San Antón y Tiradores (Troitiño, M., 1984).

Toledo tuvo un primer proyecto de Plan General en 1943, pero no llegó a estar vigente por la incidencia sobre la ciudad de la normativa de conservación y protección de paisaje derivada de su temprana declaración como conjunto histórico artístico en 1940. Aquel proyecto se limitaba al casco antiguo y no se interesaba por el espacio situado más allá de la muralla.

Por su parte, el primer Plan General de Albacete es de 1950. Influido por la concepción urbanística de los Planes de Ensanche del XIX en cuanto a la preocupación fundamental por las alineaciones y la regularización del entramado, sirvió para ordenar el espacio que se venía configurando desde los años treinta entre el centro histórico, el ferrocarril y la carretera de circunvalación. El Plan consolidó la estructura radioconcéntrica del plano y organizó el entramado en orden cerrado, a base de manzanas con cuatro fachadas y patio interior, edificios de 4 a 5 alturas, excepto en las vías próximas al parque "Abelardo Sánchez", la zona de mayor categoría social, donde se aceptaban alturas de más de 10 pisos (Panadero, M., 1976). 
El principal impacto del planeamiento en la forma de las ciudades castellano-manchegas se debe a los Planes Generales de Ordenación Urbana posteriores a la aprobación de Ley del Suelo de 1956, siguiendo en los años sesenta, los de mayor crecimiento demográfico y económico del país, las directrices marcadas por la Dirección General de Urbanismo. Todos ellos han marcado decisivamente el paisaje de las ciudades al imponer un nuevo modelo urbano, el "funcionalista", que resulta de las ideas de Le Corbusier y Gropius a través de la Carta de Atenas y se difunde después de la Segunda Guerra Mundial por todo el Planeta.

Dentro del nuevo marco conceptual, la ciudad pasaba a ser concebida como un todo que internamente se diferenciaba en zonas de usos del suelo distintas, con un amplio desarrollo del entramado abierto y la utilización de tipologías edificatorias variadas: manzana cerrada para usos intensivos, manzanas abiertas para usos semintensivos, bloques y torres para polígonos residenciales, conforme a los principios del "open planning", con espacios libres para aparcamientos, zonas verdes y equipamientos colectivos, edificación extensiva para construcciones bajas alejadas del centro, y finalmente, viviendas unifamiliares para periferias.

Las concepciones organicistas, inspiradas en las propuestas del norteamericano Clarence Perry y difundidas en España por Cesar Cort y Gabriel Alomar, entre otros, se plasmaban en la descomposición nuclear de la ciudad y en la jerarquización de las zonas residenciales: desde unidades vecinales a unidades de barrio y de distrito, cada una de ellas prevista para un número determinado de habitantes y dotadas de equipamientos y servicios acordes con las necesidades de la población. De ese modo se pretendía potenciar las relaciones sociales y se intentaban evitar los problemas de desvertabración y anomía que provocaba la vida en las ciudades según interpretaciones wirthianas. Por último, la circulación automovilística era separada de la peatonal y el viario adoptaba una estructura jerarquizada, diferenciándose las vías de circulación general de las de acceso a cada una de las zonas.

Los Planes Generales de Guadalajara (1962), Albacete (1963 y 1974), Ciudad Real (1963), Cuenca (1963), Toledo (1964) y sus sucesivas adaptaciones a las modificaciones impuestas por las revisiones de la Ley del Suelo de 1975 y 1990, han creado zonas residenciales e industriales que ya suponen la parte más extensa de cada una de esas ciudades. Entre los barrios que surgen a apartir de entonces y que hoy se hallan plenamente consolidados, por citar algunos a modo de ejemplo, figuran los de Palomarejos, Santa Teresa o Buenavista en Toledo, los polígonos INUR de 2000 viviendas y de San Antonio en Cuenca, el polígono del Torreón 
en Ciudad Real, los barrios de Bellavista, la urbanización de los Manantiales y la zona sureste de las Adoratrices en Guadalajara, y los barrios de Pedro La Mata, Hermanos Falcón, o de las «600 viviendas" en Albacete, al otro lado de la carretera de Madrid-Alicante, desbordando la circunvalación hacia el Sur. Resultado de todo ello es una forma cada vez más extensa y difusa a la que también han contribuido la generalización del uso del automóvil y el gusto por la vivienda unifamiliar en urbanizaciones de adosados o exentos desde comportamientos rururbanos y modelos de vida importados que ensalzan el contacto con la naturaleza.

La principal diferencia entre unos y otros barrios, entre unas y otras zonas residenciales, estriba en la calídad de la construcción de sus viviendas, en el predominio del entramado abierto o cerrado, en la densidad de edificación y en el nivel de equipamientos urbanos. Los peores desde el punto de vista paisajístico corresponden a las promociones oficiales más antiguas y más alejadas del centro, destinadas en sus orígenes a cubrir la demanda de alojamiento de sectores sociales de rentas bajas. Durante mucho tiempo y en una proporción elevada de casos el nivel de equipamiento de estos barrios fue deficitario y sólo ha mejorado con el paso del tiempo gracias a la presión vecinal.

Población de los Municipios con planeamiento en \% (1995)

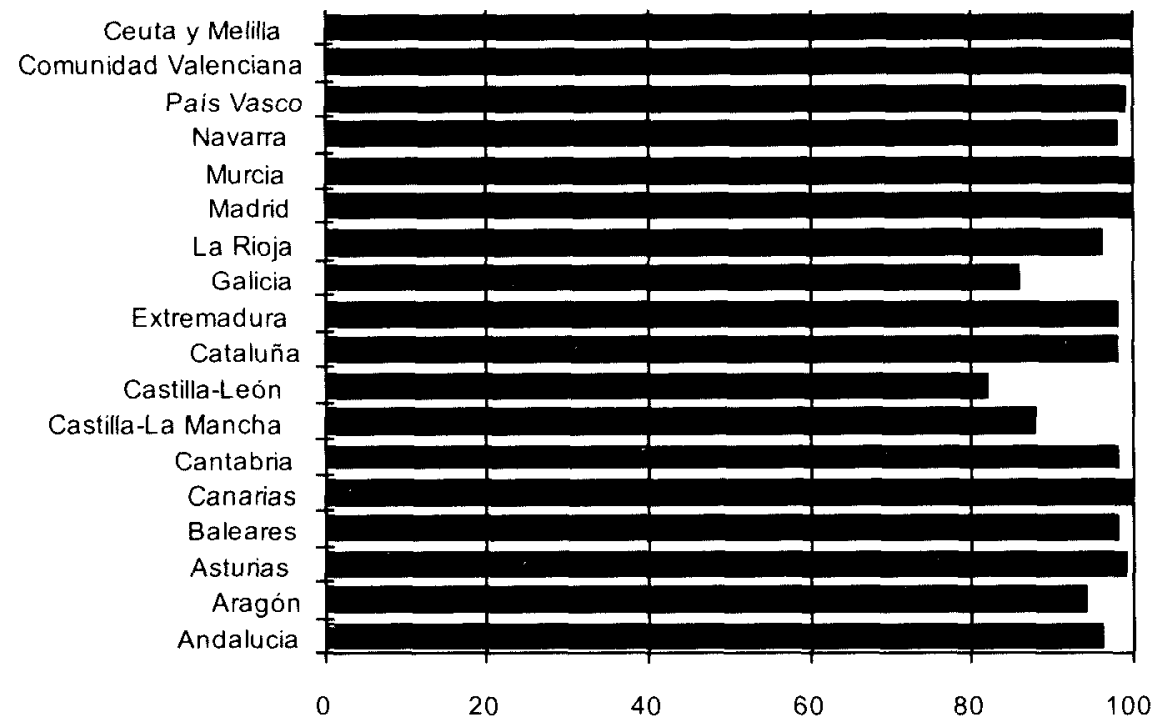

Fuente: MOPUTMA 


\section{POLIGGONOS INDUSTRIALES Y MIXTOS}

El Plan de Descongestión de Madrid de 1959 ha contribuido también indirectamente a configurar la forma extensa y zonificada que tienen en la actualidad las ciudades de Castilla La Mancha. Los polígonos mixtos, de carácter residencial e industrial, creados por la Gerencia de Urbanización en Guadalajara, Toledo, Alcázar de San Juan y Manzanares, no fueron capaces de frenar el excesivo crecimiento industrial y poblacional de la capital de España tal como se pretendió; su desarrollo urbanístico fue lento y en ciertos casos alejado de los primeros objetivos, pero todos ellos introdujeron esquemas de organización del territorio relacionados con el funcionalismo que refuerzan los modelos de ciudad difundidos por los Planes Generales de Ordenación Urbana.

El polígono mixto de Santa Maria de Benquerencia en Toledo, con una superficie de $6.700 .000 \mathrm{~m}^{2}$ y unas previsiones de población para más de 90.000 habitantes, ronda en la actualidad los 20.000 y todavía hoy existen parcelas sin ocupar. La situación de los polígonos de Alcázar de San Juan, y Manzanares respecto a las previsiones iniciales todavía es peor debido a su alejamiento de la aglomeración madrileña y a su escaso dinamismo demográfico El primero de ellos cuenta con una superficie urbanizada de $4.685 .000 \mathrm{~m}^{2}$, su zona residencial debía alojar a 60.000 personas y prevía la creación de 9000 puestos de trabajo. El segundo, el de Manzanares, ocupa una extensión de $3.276 .500 \mathrm{~m}^{2}$ y debía haber proporcionado 13.000 empleos (Zárate, A., 1984).

Sólo los polígonos de descongestión de Guadalajara, el del Balconcillo, al suroeste de la ciudad, entre el río, la autovía y el casco antiguo, con una superficie residencial de $1.366 .000 \mathrm{~m}^{2}$ para una población previstas de 60.000 h., y el del Henares, al Nordeste, al otro lado del río y de carácter exclusivamente industrial, con una extensión de $905.576 \mathrm{~m}^{2}$, se hallan totalmente ocupados. El éxito de estos polígonos, a diferencia de los anteriores, se ha debido fundamentalemente a la renta de situación de Guadalajara, cerca de Madrid, y a su buena localización sobre el eje de comunicaciones Madrid-Zaragoza-Barcelona, convertido en corredor industrial del Henares, al socaire del proceso de industrialización de los años sesenta.

La política de industrialización de los años sesenta, en el marco de la planificación del desarrollo y dentro del proceso general de liberali- 
zación de la economía y de aspiración a un reequilibrio territorial, impulsó la aprobación y construcción de polígonos industriales en Talavera de la Reina, Albacete, Cuenca y otras localidades castellanomanchegas, la mayoria por parte de la iniciativa oficial pero también algunos por parte de la iniciativa privada. La tendencia del planeamiento "funcionalista" a sacar las industrias del interior de las ciudades y a concentrarlas espacialmente en zonas de uso industrial justificó la creación de muchas de estas zonas industriales periurbanas. Hoy, muchos de estos espacios industriales se encuentran en una situación respecto a sus previsiones iniciales parecida a la de los polígonos de descongestión de Madrid. La crisis económica de finales de los años setenta, el cambio de ciclo demográfico y la sustitución del capitalismo fordista por el capitalismo flexible frenaron el proceso de industrialización tal como se había desarrollado en la década de los sesenta. Asi, el polígono mixto de Albacete, de carácter residencial e industrial, previsto para 60.000 habitantes por la Gerencia de Urbanización, estaba poco ocupado en 1981 y en su zona industrial sólo había 13 empresas que empleaban a 486 trabajadores.

Sin embargo, desde el punto de vista morfológico, muchos de estos polígonos de carácter mixto, residencial e industrial, tienen un valor urbanistico añadido al que resulta de su identificación con el «funcionalismo", y es su relación con patrones de urbanización inspirados en los modelos de ciudad lineal que defendieron los "modernistas" y "desurbanistas" soviéticos en los años treinta, sobre todo el arquitecto Miltjutin, como instrumento para superar la contradicción dialéctica campo-ciudad (Galantay, 1977). De manera muy semejante a aquellos esquemas, los diferentes usos del suelo (residencial, industrial, equipamientos) se disponen en bandas longitudinales y paralelas separadas por una zona verde y unos ejes de comunicaciones que se apoyan en un tendido ferroviario y en la proximidad a alguna carretera existente con anterioridad.

Dentro de las zonas industriales las parcelas se diferencian por su tamaño en función de las dimensiones de las industrias que se preveían instalar: grandes industrias procedentes del exterior, incluso multinacionales, industrias de tipo medio, y almacenes y pequeñas industrias procedentes del interior de las respectivas ciudades. El polígono de Toledo, aprobado en 1964, a $8 \mathrm{~km}$. de la ciudad y separada de ella por una zona verde de protección de paisaje, y el polígono de Alcázar de San Juan, aprobado en dos fases, 1963 y 1964, al noroeste de la ciudad tradicional y junto a las instalaciones ferroviarias, son dos ejemplos representativos de este modelo morfológico. 


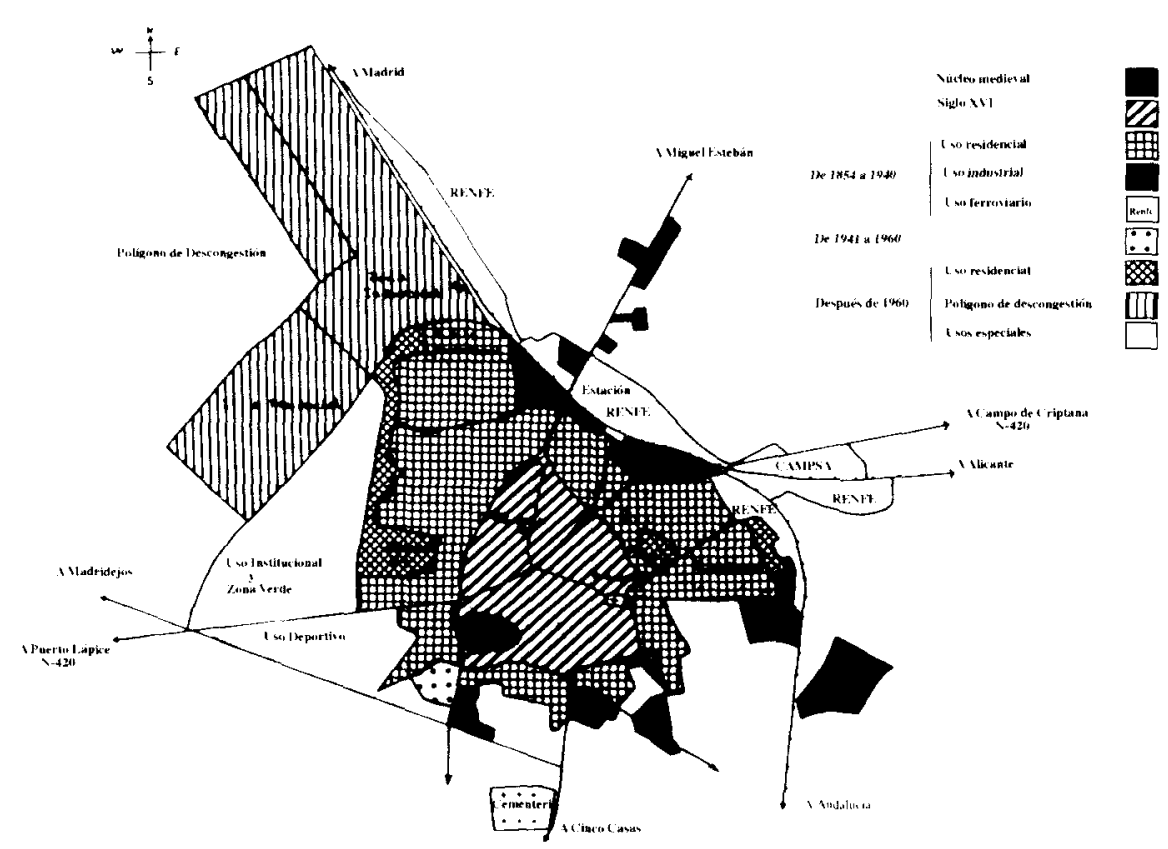

Figura 4. Desarrollo urbano Alcázar de San Juan.

\section{RECUPERACIÓN DE LA CIUDAD CONSTRUIDA Y REVISIÓN DEL PLANEAMIENTO}

La crisis económica de los años setenta, con la subida de los precios del petróleo, cuestionó por primera vez el modelo de ciudad dispersa al que se tacha de despilfarrador por su elevado consumo de energía y los elevados costes económicos y sociales que comportan los desplazamientos entre unas y otras zonas. A la vez, corrientes historicistas empezaron a reivindicar la recuperación de los centros históricos a través de políticas de rehabilitación capaces de detener su avanzado estado de degradación material y deterioro social. De uno y otro modo, se insistía en la necesidad de poner coto a la expansión sin límites de la ciudad mediante la continua oferta de suelo urbanizable, tal como se venía haciendo hasta entonces; a partir de este momento se considera prioritario la recuperación del centro y la terminación de la ciudad existente, dotándola de las infraestructuras, equipamientos y servicios necesarios

El rápido descenso del crecimiento de población por cambios en el comportamiento ante la natalidad y el final de los grandes movimientos 
migratorios campo-ciudad justificaban también una menor demanda de suelo urbano nuevo. Además, la constitución de los primeros ayuntamientos democráticos en 1979, con el triunfo de los partidos de izquierda, incorporaron una visión de la ciudad que proponia la recuperación de los espacios construidos y anteponía los valores de uso a los valores de cambio en el tratamiento del suelo urbano. Todo ello se materializó en una revisión del planeamiento anterior, también favorecida por la necesidad de ajustar el planeamiento a la nueva Ley del Suelo de 1975.

\begin{tabular}{lccccc}
\hline \multicolumn{5}{c}{ PLANEAMIENTO EN CASTILLA-LA MANCHA (1995) } \\
\hline PROVINCIAS & PLANGRAL & NN.SS & $\begin{array}{c}\text { D.S.U. } \\
\text { PLANEAMIENTO }\end{array}$ & SIN & TOTAL \\
\hline ALBACETE & 4 & 24 & 40 & 20 & 86 \\
CIUDAD REAL & 5 & 30 & 52 & 13 & 100 \\
CUENCA & 4 & 60 & 61 & 113 & 238 \\
TOLEDO & 2 & 102 & 21 & 79 & 204 \\
GUADALAJARA & 2 & 74 & 46 & 165 & 287 \\
CAST.-LA MANCHA & 16 & 290 & 221 & 390 & 915 \\
\hline
\end{tabular}

Fuente: Consejería Obras Públicas

Dentro de nuestra región, los Planes Generales aprobados a partir de los años ochenta (Albacete, 1985; Cuenca, 1987; Toledo, 1986; Ciudad Real, 1987; Puertollano, 1990) incorporaron directamente criterios nuevos del planeamiento e indirectamente a través del efecto demostración ejercido por el Plan General de Ordenación Urbana de Madrid de 1985, cuyos objetivos se resumian en los lemas "Terminar la ciudad" y "Recuperar el centro". Siguiendo las nuevas pautas de organización territorial, en todas las ciudades castellano-manchegas se recalificaron suelos con la idea fundamental de aprovechar los espacios libres espacios existentes dentro del continuo urbano y soldar áreas inconexas. La preocupación por la mejora de la circulación se ha materializado en la modernización de los transportes colectivos y en el acondicionamiento de las infraestructuras viarias para hacer frente a un creciente aumento de la circulación rodada. La mejora de los accesos urbanos y la realización de vías de circunvalación, acometidas por el Ministerio de Fomento y financiadas en gran parte por los Fondos Estructurales de la Unión Europea, han contribuido a los cambios más recientes de la forma urbana y han transformado en muchos casos la imagen de nuestras ciudades.

El Plan General de Toledo de 1986 ha compactado en pocos años la forma de esta ciudad al hacer desaparecer muchos de los espacios vacíos 
existentes anteriormente. Mediante el sistema de permuta se han incorporado al continuo urbano suelos de uso militar que se convierten en parques y zonas residenciales. Los mecanismos de recalificación previstos por la propia legislación y el deseo de dar nuevo uso a las instalaciones de la antigua Fábrica de Armas en la Vega Baja del Tajo han abierto el camino a la ocupación de zonas consideradas de protección de paisaje por las Instruccciones de la Dirección General de Bellas Artes de 1968, a pesar de poner en peligro la pervivencia de panorámicas de valor ambiental inmortalizadas por pintores del XIX entre los que destaca Aureliano Beruete.

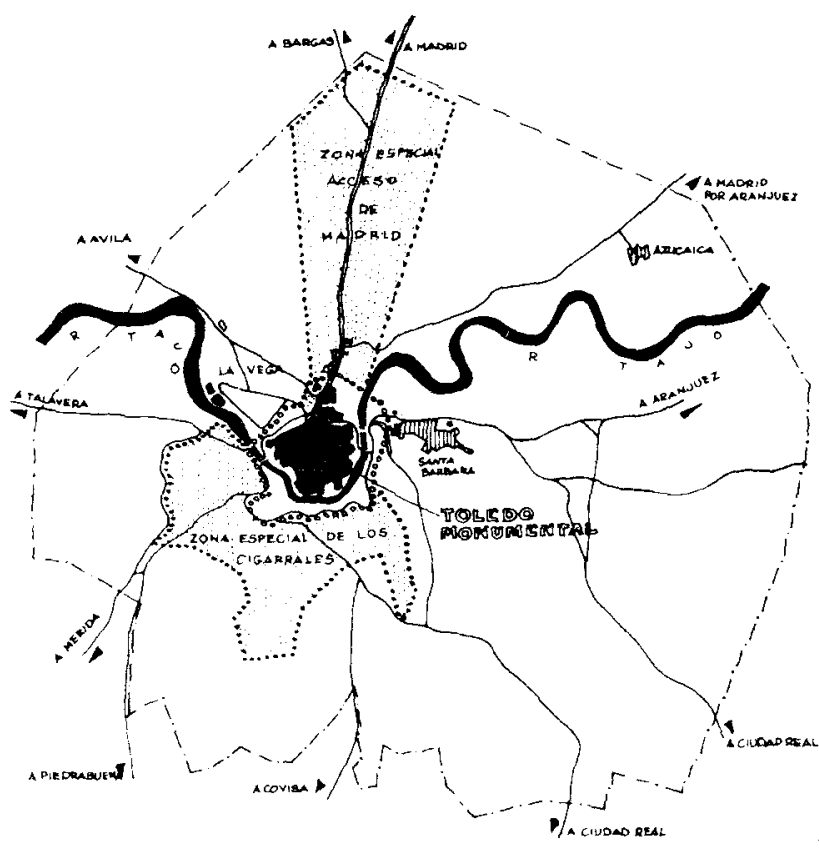

Figura 5. Zonas de protección del conjunto histórico-artístico de Toledo.

Entre los objetivos explicitados por el PGOU de Albacete de 1985, en consonancia con el denominado "planeamiento de la austeridad", figuran el control de la residencia dispersa, la lucha contra la segregación socioespacial, la construcción de un tejido urbano más coherente, la protección, defensa y conservación del patrimonio edificado. Para ello se apuesta por el mantenimiento de las actividades existentes dentro del casco 
urbano, evitando la desertización de las áreas centrales y el ensanche, y se subraya la necesidad de conservar la población en sus lugares tradicionales de residencia histórica. Se trata de evitar la expulsión de las capas populares a la periferia, como ya ha sucedido en otras ciudades, y se intenta potenciar la vida urbana fomentando la multifuncionalidad y la variedad de usos dentro de unas mismas zonas.

A diferencia del planeamiento anterior, el vigente Plan General de Albacete prioriza las actuaciones urbanísticas sobre los espacios ya construidos del centro y de las periferias. Se presta especial atención al Norte, donde los usos del suelo son muy variados y donde el traslado de la estación a otro emplazamiento originó en su momento un nuevo ensanche sobre el que se sitúan la zona de equipamiento y de calidad del Parque Lineal, el polígono de San Antón, con densidades medias y espacios libres, y más al Sur, el barrio de autoconstrucción e infravivienda de la Estrella y la actuación oficial de las 600 , de bajos niveles de calidad ambiental. En la periferia Sur, se abordan los problemas de los barrios marginales, de crecimiento espontáneo y autoconstrucción, que surgieron mucho antes más allá de la carretera de circunvalación. También se pretende soldar el barrio del Pilar y el polígono industrial de Campollano al continuo urbano, con la reutilización de las parcelas industriales sin usos para dotación de servicios y equipamientos de la ciudad.

Los Planes Generales de Guadalajara (1983), Ciudad Real (1987) y Cuenca (1987) proponen objetivos y actuaciones análogas. En Ciudad Real, su escaso crecimiento durante el pasado ha aconsejado aprovechar urbanísticamente el abundante suelo libre existente dentro y al otro lado de la ronda. En el centro, se consolidan los usos intensivos, y en las diferentes zonas, se mantienen las tipologías edificatorias heredadas. Fuera de la ronda, se reconoce un claro predominio a las viviendas unifamiliares de una planta. Las construcciones multifamiliares, a base de bloques abiertos, se concentran en el polígono de la Granja, barrios de Pío XIl y de los Angeles, salida de la carretera de Toledo y polígono Torreón del Alcázar. En la nueva periferia proliferan las edificaciones aisladas de servicios, los equipamientos, entre ellos el Campus Universitario. Las actividades industriales se disponen preferentemente en los accesos de las carreteras de Carrión y de Toledo.

En Cuenca, las principales innovaciones paisajísticas introducidas por el Plan General de 1987, corresponden a la urbanización de un polígono industrial en la carretera de Alcázar de San Juan para sanear y consolidar el área, a la construcción de unos polígonos residenciales, la creación de un complejo turístico de vacaciones en El Cambrón y un camping junto al 
río Chillón. El Plan diseña también el trazado de una vía de circunvalación y prevé la elaboración de Planes Especiales para la protección y regulación de usos y edificaciones en la ciudad antigua y en las hoces.

En el caso de Talavera de la Reina, la falta de instrumentos administrativos de referencia y control hasta el Avance de Normas Subsidiarias de 1982 y la aprobación de su primer Plan General de Ordenación Urbana en 1994, propició, sobre todo en los años sesenta y setenta, los de mayor crecimiento, los abusos en los aprovechamientos edificatorios del suelo, la transformación morfológica del centro y la excesiva construcción en altura. Hoy, cuando prácticamente se halla edificado todo el espacio libre que hasta los años 60 existía entre el casco urbano de entonces y la linea del ferrocarril, las nuevas urbanizaciones se extienden hacia el Este y Oeste.

Los planteamientos de organización territorial contemplados en su reciente Plan General responden a los mismos criterios que en el resto de las ciudades castellano-manchegas. También en Talavera de la Reina se da prioridad a la mejora de los espacios existentes y a la revitalización del centro, con operaciones dirigidas a conservar la población tradicional y recuperar construcciones del pasado. En la periferia urbana ha tenido especial importancia la construcción de un nuevo Mercado Nacional de Ganados sobre una superficie de más de $173.0000 \mathrm{~m}^{2}$, en el $\mathrm{Km} 128$ de la autovía E-90. Este Mercado, inaugurado en 1994, se integra en la red de mercados de la Unión Europea y pretende potenciar la importancia ganadera de la ciudad, desde que el rey Sancho IV, le concediera en 1294 la celebración de una feria anual "ocho dias antes de San Andrés y ocho días después".

Por último, como otros rasgos comunes del nuevo planeamiento, presentes en todas las ciudades, hay que señalar la preferencia por las actuaciones de detalle en base a sistemas geométricos centralizados y la importancia concedida al diseño arquitectónico y urbanístico. En todas las nuevas periferias urbanas, la calle y la manzana reaparecen como elementos de ordenación que aspiran a recuperar la mezcla funcional y social característica de las ciudades tradicionales frente a la excesiva segregación y zonificación de la ciudad funcional. No obstante no se trata de una mera imitación del pasado ya que la manzana actual es generalmente concebida como un elemento autónomo en sí mismo, que se estructura con carácter autosuficiente entorno a un gran patio central en respuesta a la tendencia introspectiva de la arquitectura. La barriada de las "Malvinas" en Toledo es un ejemplo bien representativo de esta forma de organización espacial. 


\section{COMPORTAMIENTOS RURURBANOS Y CONTRAURBANIZACIÓN}

Otro de los factores que afectan a la forma de nuestras ciudades es el creciente comportamiento rururbano de la sociedad actual. Siguiendo modelos anglosajones de proximidad con la naturaleza y modas ecologistas o pseudoecologistas difundidas por los medios de comunicación de masas, cada vez son más valorados los habitats en viviendas unifamiliares, en chalets exentos, en relación también con la tradición higienista de la ciudad-jardín, o en chalets adosados. En ambos casos, se construyen sobre antiguos suelos de uso rural recalificados por el planeamiento oficial o por otros procedimientos, dentro del propio término al que pertenece la ciudad principal o en municipios vecinos.

Actualmente, las urbanizaciones de unifamiliares proliferan en todas las periferias castellano-manchegas, con tipologías muy variadas en función de la naturaleza oficial o privada de las promociones, del rango social de la demanda para la que son concebidas, del grado de integración dentro del planeamiento urbano y de la mayor o menor industrialización en su proceso de edificación. Argés, Nambroca, Olías del rey, Bargas, localidades inmediatas a Toledo que han perdido buena parte su carácter rural y se han convertido en barrios dormitorio de la capital regional, ofrecen un amplio muestrario de estas tipologías residenciales.

La construcción de unifamiliares es también impulsada por la aplicación de técnicas de edificación en serie que abaratan sus costes y por el planeamiento oficial que reserva amplias superficies en las periferias para usos residenciales poco intensivos. La propia Junta de Comunidades ha contribuido a difudir este modelo de urbanización por las diferentes localidades de la región al adoptar frecuentemente sus tipologías para la construcción de viviendas sociales.

A todo ello habría que añadir, el interés de promotores e inmobiliarias por construir sobre suelos baratos, lejos de los espacios consolidados, para aumentar los rendimientos de su inversión, y el deseo de los particulares de obtener viviendas de mayor tamaño y menor coste que las que pueden encontrar en las áreas centrales. El resultado es un aumento de la forma dispersa de la ciudad, a pesar de las repetidas críticas al modelo de ciudad extensa y de los intentos por parte del más reciente planeamiento de compactar los espacios construidos en un afán por rentabilizar las infraestructuras existentes y reducir los despalzamientos intraurbanos. 


\section{PROTECCIÓN DEL PATRIMONIO HEREDADO Y FORMA URBANA}

En una región como Castilla-La Mancha, la legislación de protección del patrimonio histórico artístico ha desempeñado un papel importante en la forma de las ciudades y localidades que gozan de alguna declaración de esta naturaleza. La calificación de Toledo como Conjunto Histórico Artístico por Decreto de 4 de marzo de 1940 y de Cuenca como Paraje Pintoresco en 1963 han evitado transformaciones paisajísticas traumáticas de sus cascos antiguos, como las sufridas por otras áreas centrales no protegidas en los años del desarrollismo. No obstante, también es cierto que la rigidez del marco legal y la insuficiencia de las ayudas concedidas por la administración a los particulares para hacer frente a los costes de la conservación han dificultado la revitalización funcional de los centros históricos y han contribuido a su abandono poblacional. La conservación del patrimonio residencial heredado se ha convertido en una carga que desborda la capacidad económica de la mayoría de los propietarios y habitantes de estas localidades, por lo que más pronto o más tarde se produce el vaciamiento demográfico y en el mejor de los casos la sustitución de usos residenciales por usos terciarios, en una elevada proporción de carácter institucional, como sucede en Toledo. (Zárate, A., 1994).

La renovación arquitectónica o la simple obtención de licencias de obras resulta un proceso lento y complicado para los ciudadanos por los mecanismos de control establecidos por la legislación y por la intervención de diferentes administraciones para su aprobación. Por otra parte, las ayudas prestadas a la rehabilitación por los organismos oficiales aún resultan insuficientes por la riqueza y complejidad del patrimonio heredado, a pesar de la relativa mejora que han supuesto los Planes "Urban" y la aplicación de programas como "Toledo, Cuenca, Ciudad Real... a plena luz".

La necesidad de respetar las características arquitectónicas de los viejos edificios, con estructuras de madera, muros de mampostería, ladrillo y piedra en fachadas, forjados de hierro, hacen imposible la aplicación de técnicas de construcción industrializadas y exigen la utilización de una mano de obra muy especializada, con lo que la rehabilitación resulta técnicamente complicada y cara. Igualmente la preocupación por mantener las tipologías edificatorias heredadas, sobre parcelas excesivamente irregulares y en muchos casos calles estrechas, sin apenas luz, dificulta tremendamente la mejora de las condiciones de habitabilidad de las viviendas antiguas.

La legislación de conservación del patrimonio histórico-artístico también repercute en la morfología a través del establecimiento de zonas de protección de paisaje que prohiben la construcción dentro de ellas y limitan 
la altura y volumen de la edificación dentro de su área de influencia. Así, las Instrucciones de la Dirección General de Bellas Artes de 1968 para Toledo establecieron amplias zonas de protección de paisaje dentro de las que se incluyen el Circo Romano y la antigua Fábrica de Armas. Más allá, hacia el Norte, se establecía unas zonas de influencia donde la altura se limita a 5 plantas. De ese modo se ha favorecido la forma extensa y difusa de la ciudad, en contraste con la forma compacta del pasado. La ciudad se desparrama lejos del centro histórico por la Vega del Tajo, en sentido Este-Oeste, y hacia el Norte, por la carretera de Madrid.

La existencia de numerosos terrenos militares y la prohibición de construir en sus inmediaciones, no siempre respetada, también favoreció la forma especialmente dispersa de Toledo.

\section{LAS AGROCIUDADES}

Fuera de las capitales de provincia y de las ciudades de mayor rango, como Talavera y Puertollano, la expansión urbana ha sido escasa por un crecimiento poblacional muy pequeño desde los años cincuenta y un reducido dinamismo económico, si exceptuamos unas pocas localidades entre las que destaca lllescas por el efecto de frontera debido a su proximidad a Madrid y a las facilidades fiscales concedidas por la Junta de Comunidades para la instalación de industrias dentro de Castilla-La Mancha.

\section{Agrociudades}

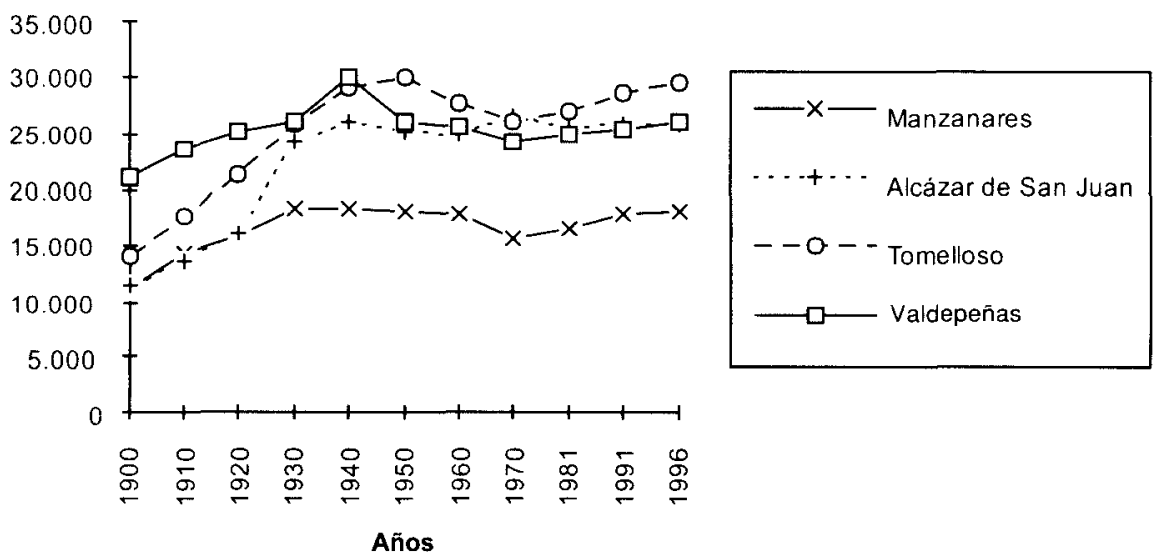

Fuente: Censos de Población y Padrón Municipal. 
Todavía hoy, la inmensa mayoría de las poblaciones manchegas de más de 10.000 habitantes conserva el carácter y paisaje de agrociudades que las ha definido tradicionalmente, a pesar de que su población agrícola ha disminuido mucho, el empleo en el sector servicios ha aumentado y la actividad industrial tiene cierta importancia en Alcázar de San Juan y Manzanares. Todas estas localidades conservan la tradicional forma compacta, perviven las tipologías de las casas rurales manchegas con sus correspondientes variantes regionales o comarcales, y mantienen una elevada proporción de espacios libres en el interior, debido al uso poco intensivo del suelo, entre otras razones, por la escasa presión demográfica.

En Alcázar de San Juan, Manzanares, Valdepeñas, La Robla, La Solana, Campo de Criptana, Tomelloso, Socuellamos, Tarancón, más del $90 \%$ de sus construcciones son menores de dos plantas. Siguen siendo paisajísticamente predominantes las viejas casas solariegas, con habitaciones organizadas en torno a un patio central, y las casas tradicionales de menor categoría social, de una o dos plantas, con fachadas a la calle y patios interiores. Las casas se ordenan en manzanas cerradas y calles rectas y anchas. Muchos de los edificios de una planta corresponden a bodegas, talleres 0 almacenes de aperos y maquinaria agricola, en especial hacia a las afueras de las localidades, en las inmediaciones de las carreteras y de las vias del ferrocarril.

La edificación de altura, de mas de 3 plantas, corresponde a bloques de viviendas que se levantan en las periferias y a conjuntos multifamiliares construidos en las calles principales, próximas al centro, como resultado de pequeños procesos de renovación morfológica y funcional por las ventajas de la centralidad y el desarrollo de los servicios. Las características arquitectónicas de estas construcciones dependen de los años en que se levantaron, de la naturaleza de las promociones que las dieron origen, de las orientaciones del planeamiento oficial y de los comportamientos imitativos de las modos de vida de la gran ciudad.

En la mayoría de las agrociudades se reconocen a pequeña escala muchas de las tipologías existentes en las ciudades principales, desde las bloques construidos por la Obra Sindical del Hogar y el Instituto Nacional de la Vivienda a las recientes urbanizaciones realizadas bajo el patrocinio de la Junta de Comunidades.

\section{POBLADOS DE COLONIZACIÓN}

Una última tipología constructiva dentro de la región está constituida por los poblados levantados en la posguerra por el Instituto Nacional de 
Colonización, como Cañada de Agra, en la zona del canal de Hellín (Albacete), los LLanos del Caudillo, a $12 \mathrm{~km}$. al norte de Manzanares (Ciudad Real) en la provincia de Ciudad Real, o Torres de Salina, en la zona del Alberche (Toledo). Todos ellos forman conjuntos residenciales de interés histórico relacionados con la puesta en regadío y mejora de tierras dentro la ideologia agrarista y de la política de autarquía de la época.

Los entramados de estos poblados responden a un diseño unitario y a fórmulas variadas en la disposición del viario, desde una estructura regular en cuadrícula a trazados curvos que enlazan con planteamientos racionalistas. Las características arquitectónicas son más parecidas. Las casas responden a modelos casticistas que reflejan la arquitectura más popular y genuina de la zona siguiendo las directrices de la Dirección General de Arquitectura y los planteamientos teóricos del primer Franquismo. Las viviendas tienen varios tamaños en función del número de habitantes pero su distribución es muy semejante: una planta, cocina comedor y tres dormitorios como mínimo. La iglesia y la escuela ocupan siempre un lugar destacado dentro de estos poblados y todos ellos disponían de los equipamientos e infraestructuras imprescindibles: comercio, taller de reparación de maquinaria, zonas verdes y deportivas.

\section{CONCLUSIÓN: DE LA CIUDAD COMPACTA A LA CIUDAD DISPERSA}

En el umbral del siglo xxI, las ciudades de Castilla-La Mancha muestran en su forma la huella de los diferentes procesos de urbanización que se han sucedido a través del tiempo, destacando dentro de ellas y de manera especial en algunas sus centros históricos por la importancia del patrimonio urbanístico e histórico acumulado y la belleza y espectacularidad de sus emplazamientos. En este sentido también hay que tener en cuenta el interés de muchas localidades de menor rango dentro de la jerarquía, como Ocaña, Tembleque, Almagro, Villanueva de los Infantes, Siguenza, Chinchilla, entre otras, que constituyen un muestrario de respuestas urbanísticas a necesidades concretas de las sociedades del pasado, en épocas en que su posición en el sistema urbano era diferente al actual. Plazas mayores, equipamientos colectivos, iglesias, palacios, modelan la forma de estas localidades y las singularizan con fuerza dentro del patrimonio urbano español.

Por otra parte, las ciudades principales castellano-manchegas reflejan plenamente las pulsaciones actuales de la dinámica urbana y los efectos de los cambios más recientes del sistema productivo a través de la contraposición de tendencias de "reurbanización" y "contraurbanización". 
Mientras se observan fenómenos de interés por la conservación, revitalización y recuperación de los espacios construidos, que favorecen el relleno de los intersticios y la forma compacta, también se producen fenómenos de suburbanización y contraurbanización que llevan a extender cada vez más lejos los límites de las ciudades y a configurarlas de forma extensa y difusa.

\section{BIBLIOGRAFIA}

Alomar, G. (1961): Socilogía urbanistica. Ed. Aguilar, Madrid.

DIAZ Nosty, B. Y SUEIRO, D. (1977): La historia del franquismo. Ed. Sedmay, Madrid.

EStebanez Alvarez, J. (1989): Las ciudades, morfología y estructura. Ed. Sintesis, Madrid.

Garcia Ballesteros, A. (1978): Geografía urbana de Guadalajara. Fundación Universitaria Española, Madrid.

Garcia Martinez, C. (1995): "El centro histórico de Albacete: Carretas". En Las Ciudades españolas a finales del siglo XX. págs. 101-102, Universidad de Castilla La Mancha-AGE. Cuenca.

Garcia-Pablos Gonzalez-Quijano, R. (1982): "Defensa de los entornos de las ciudades monumentales. El caso de Toledo". En Defensa, protección y mejora del patrimonio histórico-artístico y arquitectónico. Ed. Colegio Oficial de Arquitectos de Madrid, Madrid, págs. 56-86.

LASSWELL, H. (1979): The signature of power. Ed. Transaction Books, New Brunswick.

LEVY, A. (1965): Psychologie sociale. Dunod, Paris.

Marin Zapata, G. (1989) Notas sobre la dinámica reciente de los cascos antiguos de las capitales de Castilla-La Mancha. En XI Congreso Nacional de Geografia, Comunicaciones, vol. III, págs. 125-143, AGE-Universidad Complutense, Madrid.

Ministerio de Hacienda (1973): Polos de desarrollo y polígonos de descongestión, Madrid.

Panadero Moya, M. (1976): La ciudad de Albacete. Caja de Ahorros Provincial de Albacete, Albacete.

Pillet CApdepon, Felix (1984): Geografia urbana de Ciudad Real. Akal Universitaria, Madrid.

SMAILES, A.E. (1966): The Geography of towns. Hutchinson, Londres.

TrOITINO VINUESA, M.A. (1984): Cuenca, evolución y crisis de una vieja ciudad castellana. MOPU, Madrid.

Zarate Martin, A. y VAzouez A. (1983): El Casco Histórico de Toledo. ¿Un Espacio Urbano Vivo?. Ed. Zocodover, Toledo, págs. 116.

Zarate MaRtín, A. (1984): "Análisis de la Dotación Funcional y Jerarquía Funcional del Espacio Urbano de Toledo mediante el Uso de Técnicas Cuantitativas". Estudios Geográficos, $n^{\circ} 176$, págs. 331-352.

ZARATE MARTin, A. (1985): "El sistema urbano». En El espacio geográfico de la provincia de Ciudad Real, págs. 349-422. Biblioteca de Autores Manchegos, Diputación de Ciudad Real.

ZARATE MARTin, A. (1989): “Toledo, entre la renovación espontánea y la rehabilitación oficial “. En Boletín de la Real Sociedad Geográfica. Tomo CXXIV-CXXV, nº 1 al 12, años 1989 y 1989 , págs. 195-210.

Zarate Martin, A. (1992): “Pintura de paisaje e imagen de España: un instrumento de análisis geográfico". En Espacio. Tiempo y Forma. Rev. de la Facultad de geografía e Historia de la UNED, Serie VI, $n^{0} 5$, págs. 41-65.

Zarate Martin. A. (1992): Teoría y práctica de la rehabilitación en España. En Boletín de la Real Sociedad Geográfica Española, vol. CXXVIII, 1992, págs. 320-359. 